\title{
Peningkatan Ekonomi Pesantren, Melalui Generasi Anti Riba Pada Siswa SMA Nurul Jadid Paiton Probolinggo
}

\author{
Muhammad Zainuddin Sunarto*1, Ahmad Nur Bustomi², Maybelline Dona Rinandha3, Ulfah \\ Shavira ${ }^{4}$, Sevi Yanti Dewi ${ }^{5}$, Mamik Sari Dewi6, Dewi Setya Ramadhania Nurjaki ${ }^{7}$ \\ 1,2,3,4,5,6,7Fakultas Agama Islam, Universitas Nurul Jadid Paiton Probolinggo \\ * zain2406@gmail.com ${ }^{1}$, ahmadbustomy14@gmail.com ${ }^{2}$, rmaybellinedona@gmail.com $^{3}$, \\ ulfahshavira12@gmail.com ${ }^{4}, \underline{\text { seviyantidewi99@gmail.com }}^{5}, \underline{\text { dewykimam6@gmail.com }}^{6}$, \\ setyad003@gmail.com7,
}

\begin{abstract}
Abstrak
Praktek riba dalam kehidupan masyarakat dinyatakan oleh Islam sebagai sesuatu yang dilarang dan merupakan salah satu permasalahan yang berkaitan dengan perekonomian. Praktik riba dianggap dapat menghalangi laju ekonomi sebagai mana riba dapat menarik seluruh pendapatan masyarakat. Larangan riba sebenarnya sudah tegas dan jelas dalam Al-Qur'an dan Hadis. Stuktur keuangan Islam berkisar pada larangan atas penghasilan apapun yang berasal dari pinjaman/utang (riba) dan legalitas riba. Riba yang secara umum dikenal sebagai bunga dipahami sebagai tambahan yang diambil sebagai premi dari debitur. Pelarangan riba, pada hakekatnya adalah penghapusan ketidakadilan dan penegakan keadilan dalam ekonomi. Lulusan dari SMA Nurul Jadid selain menjadi alim sesuai jurusannya, namun juga harus terdidik dari sisi karakternya. Pada hal tentang transaksi Islam, SMA Nurul Jadid juga mempraktekkan transaksi ekonomi Islam, hal ini diwujudkan dari transaksi yang berlaku di Koperasi sekolah tersebut, selain itu pemahaman tentan perkara riba, ternyata masih minim oleh siswa tersebut. Dalam konteks internal, perlu adanya pendampingan terhadap generasi muda, untuk bisa memberikan edukasi awal tentang bahaya riba terkhusus pada internal PP Nurul Jadid. Fokus pada pengabdian ini, adalah siswa SMA Nurul Jadid Paiton Probolinggo, nantinya diharapkan para siswa tersebut memiliki pemahaman dan pandangan tentang bahaya riba pada transaksi yang akan dilakukan dikemudian.
\end{abstract}

Kata kunci: Anti Riba, Ekonomi, Pesantren, SMA Nurul Jadid

\begin{abstract}
The practice of usury in people's lives is declared by Islam as something that is prohibited and is one of the problems related to the economy. The practice of usury is considered to be able to hinder the pace of the economy as usury can attract all people's income. The prohibition of usury has actually been firmly and clearly stated in the Qur'an and Hadith. The structure of Islamic finance revolves around the prohibition of any income derived from loans/debt (usury) and the legality of usury. Riba which is generally known as interest is understood as an addition taken as a premium from the debtor. The prohibition of usury is essentially the elimination of injustice and the enforcement of justice in the economy. Graduates from SMA Nurul Jadid in addition to being pious according to their majors, but also must be educated in terms of character. In terms of Islamic transactions, SMA Nurul Jadid also practices Islamic economic transactions, this is manifested in the transactions that apply in the school's cooperative, in addition to understanding the case of usury, it turns out that the students are still minimal. In the internal context, it is necessary to provide assistance to the younger generation, to be able to provide initial education about the dangers of usury, especially in the internal PP Nurul Jadid. The focus of this service is the students of SMA Nurul Jadid Paiton Probolinggo, later it is hoped that these students will have an understanding and view of the dangers of usury in transactions that will be carried out in the future.
\end{abstract}

Keywords: Anti-Riba, Economics, Islamic Boarding School, SMA Nurul Jadid

\section{PENDAHULUAN}

Kegiatan ekonomi dilakukan manusia untuk memenuhi kebutuhannya [1]. Bagi orang Islam, kegiatan ekonomi telah diatur sedemikian rupa dalam aspek ekonomi (muamalah). Ajaran Islam tentang ekonomi cukup banyak, hal ini menunjukkan bahwaperhatian Islam dalam masalah ekonomi sangat besar. Akan tetapi, tidak semua kegiatan ekonomi dibenarkan dalam Islam apalagi jika kegiatan tersebut merugikan banyak orang seperti monopoli, percaloan, perjudian dan riba, sudah pasti akan ditolak [2]. 
Makna sesungguhnya dari riba telah menjadi bahan perdebatan sejak zaman sahabat. Umar bin Khattab pernah menyesalkan karena Rasulullah S.A.W wafat sebelum sempatmemberi penjelasan yang lebih terperinci mengenai riba. Tetapi dalil Al-Qur"an menyatakan bahwa semua bentuk riba harus dikutuk. Riba mendorong manusia agar menyimpang dari jalan yang benar. Karena tukang riba diperbudak harta sehingga dia berusaha mendapatkan harta dari semua jalan. Untuk mencapai tujuannya itu, tukang riba melakukan berbagai macam cara,melanggar hukum, dan menodai dirinya sendiri. Riba sendiri tumbuh pada manusia yang rakus harta, seperti tumbuhnya loba dan kikir. Dua macam penyakit yang disebabkan adanya kerusakan dan kekikiran.[3]

Melakukan riba dalam kehidupan masyarakat dinyatakan oleh Islam sebagai sesuatu yang dilarang dan merupakan salah satu permasalahan yang berkaitan dengan perekonomian [4]. Praktik riba dianggap dapat menghalangi laju ekonomi sebagai mana riba dapat menarik seluruh pendapatan masyarakat[5]. Larangan riba sebenarnya sudah tegas dan jelas dalam $\mathrm{Al}$ Qur"an dan Hadis Nabi. Pelarangan riba tersebut dinyatakan oleh Allah dalam al-Qur'an surah Al-Baqarah ayat 278-279, yang artinya: "Wahai orang-orang yang beriman! bertakwalah kepada Allah dan tinggalkan sisa riba (yang belum dipungut) jikakamu orang beriman. (278) Jika kamu tidak melaksanakannya,maka umumkanlah perang dari Allah dan Rasul-Nya. Tetapi jika kamu bertobat, maka kamu berhak atas harta pokokmu. Kamu tidak berbuat zalim (merugikan) dan dizalimi (dirugikan) (279)".

Stuktur keuangan Islam berkisar pada larangan atas penghasilan apapun yang berasal dari pinjaman/utang (riba) dan legalitas riba. Riba yang secara umum dikenal sebagai bunga dipahami sebagai tambahan yang diambil sebagai premi dari debitur [6]. Ia mewakili atas tingkat pengembalian atas transaksi yang melibatkan pertukaran uang dengan uang, atau sebagai tambahan dalam keterlambatan pembayaran atas harga yang disepakati dari jual beli atau utang. Dalam transaksi pinjaman, pertukaran harus dalam jumlah yang sama [7]. Dalam kasus dua barang yang serupa, kondisi yang menempatkan adanya kelebihan dari salah satu pihak dilarang, bahkan ketika transaksi tersebut merupakan transaksi jual-beli, bukan pinjaman. Kelebihan tersebut dikategorikan sebagai riba. Syariah telah mengharamkannya karena menimbulkan ketidakseimbangan dalam perekonomian [8].

Terlebih lagi dengan hadirnya komunitas MAR (Masyarakat Anti Riba). MAR dipahami sebagai bagian dari komunitas kampong Syarea World (KSW), sebuah komunitas yang awalnya merupakan komunitas bagi para developers, landlords, dan business dalam bidang real estate dan property. KWS mempunyai komitmen mengembangkan bisnis syariah tanpa riba, tanpa utang, tanpa akad-akad batil. Berusaha untuk selalu menghindari unsur-unsur akad yang di larang oleh hukum syara. Peluang MAR saat ini begitu besar, di tengah meningkatnya kesadaran masyrakat, terutama kaum muslimin akan hukum-hukum transanksi riba dan yang terkait dengannya. MAR tentu saja bisa terus berkembang dan mampu memberikan sumbangsih yang baik dan nyata di tengah umat yang makin hari makin tergeliat ghiroh keislamannya [9]. Masyarakat juga makin paham dan sudah membuktikan akan ngerinya ketika terjerat riba. Banyak sekali yang merasa menyesal melakukan transanksi yang di larang oleh agama tersebut.[10]

Penelitian dan pemikiran tentang riba telah banyak dilakukan, salah satu di antaranya menurut [11] mengatakan penghapusan riba sebenarnya bertujuan untuk memajukan sistem ekonomi yang merahmati, lebih berkeadilan, hubungan sosial yang lebih berimbang serta nilainilai etika yang sejalan dengan ajaran Islam. [12] riba mengandung bahaya dan dampak baik secara mikro maupun makro. Bertahapnya pengharaman riba memberi pemahaman bahwa untuk menghadapi sistem riba juga diperlukan tahapan dan strategi yang terencana. Dan strategi utama untuk menghadapi sistem riba adalah dengan menggalakkan zakat dan sedekah.

Pelarangan riba, pada hakekatnya adalah penghapusan ketidakadilan dan penegakan keadilan dalam ekonomi. Penghapusan riba dalam ekonomi Islam dapat dimaknai sebagai penghapusan riba yang terjadi dalam jual beli dan utangpiutang. Dalam konteks ini, berbagai transaksi yang spekulatif dan mengandung unsur gharar harus dilarang. Demikian pula halnya dengan bunga - yang merupakan riba nasi"ah - secara mutlak harus dihapuskan dari perekonomian.[13] 
Bisnis tanpa riba makin terlihat geliatnya di tengah masyarakat saat ini, prospek bisnis tanpa riba, baik peluang dan tantangannya makin menunjukkan titik terang. Seiring dengan berkembangnya wacana ekonomi syariah di berbagai kalangan. Gaungnya makin ramai dan banyak dibicarakan. Terlebih lagi dengan hadirnya komunitas Masyarakat Tanpa Riba atau yang selanjutnya disebut MTR.

SMA Nurul Jadid merupakan bagian dari PP Nurul Jadid merupakan salah satu lembaga pendidikan, yang tugas utamanya adalah ta'lim (pembelajaran) dan ta'dib (pendidikan karakter). Lulusan dari SMA Nurul Jadid selain menjadi alim sesuai jurusannya, namun juga harus terdidik dari sisi karakternya. Pada hal tentang transaksi Islam, SMA Nurul Jadid juga mempraktekkan transaksi ekonomi Islam, hal ini diwujudkan dari transaksi yang berlaku di Koperasi sekolah tersebut, selain itu pemahaman tentan perkara riba, ternyata masih minim oleh siswa tersebut.

Bersumber dari pemikiran dan penelitian diatas, peneliti tertarik untuk mengkaji lebih dalam lagi bagaimana peran penting Generasi Anti Riba dalam upaya meningkatkan ekonomi pesantren di SMA Nurul Jadid Paiton Probolinggo. Target dan luaran yang dihasilkan pada program pengabdian masyarakat ini adalah peningkatan pengetahuan serta kesadaran pada Siswa SMA Nurul Jadid tentang pentingnya pengetahuan tentang transaksi yang benar yang sesuai syariat Islam dengan upaya mampu meningkatkan ekonomi pesantren pada khususnya dan ekonomi Indonesia pada umumnya.

\section{METODE}

Metode pemecahan masalah yang dilakukan pada kegiatan ini adalah dengan cara mensosialisasikan tentang riba yang bertujuan untuk memberikan pemahaman dan kesadaran siswi yang bertemakan "Generasi Anti Riba". Kegiatan yang lain adalah denganmemberikan sedikit buku, serta madin yang akan mendorong siswa SMA Nurul Jadid Paiton Probolinggo yang berada pada lingkungan pesantren, mengetahui hal hal baru yang berkaitan dengan Riba. Kegitan ini dilakukan kurang lebih selama satu bulan mulai dari perijinan dan untuk pelaksanaannya dilakukan pada tanggal 1 Februari 5 Maret 2021.

Evaluasi kegiatan ini dilakukan 3 jenis evaluasi, yaitu:

a. Evaluasi awal dilakukan dengan memberikan kesempatan kepada siswi untuk menjawab pertanyaan tentang transaksi, apa itu Riba dan lain sebagainya, serta mempraktekkan larangan Transaksi Riba. Hasil dari evaluasi ini berupa nilai tiap siswi, yang merupakan hasil dari pemahaman sebelum dilakukannya sosialisasi

b. Evaluasi proses dilakukan dengan melihat secara langsung motivasi belajar pada saat kegiatan berlangsung serta dengan melihat tanggapan siswa melalui pertanyaan siswa.

c. Evaluasi akhir dilakukan dengan memberikan kesempatan kepada siswa untuk memberikan pemahaman tersendiri tentang transaksi Riba.

d. Indikator keberhasilan kegiatan dapat dilihat dari jumlah siswa yang paham akan materi yang diberikan, sasaran yang dicapai yaitu keberhasilan dalam meningkatkan pemahaman siswa mengenai Riba. Evaluasi perubahan perilaku dilakukan dengan melihat perubahan kesadaran perilaku siswi terkait materi yang disampaikan..

\section{HASIL DAN PEMBAHASAN}

Pada tanggal 4 Februari 2021. Kegiatan KKN Mahasiswa Universitas Nurul Jadid berbasis pengabdian. Melaksanakan tugasnya di SMA Nurul Jadid dengan tema "Milenial Anti RIBA" yang di ikuti oleh 25 siswi dari kelas XII IPS 3. Tema "Generasi Anti RIBA" ini di ambil berdasarkan kehidupan sosial saat ini, yang dimana banyaknya lembaga keuangan bank baru yang beredar dimasyarakat. Dengan itu Mahasiswa Perbankan Syariah tergerak hati nya untuk mengingat kan kembali, bahwa riba adalah haram dalam islam.

Ibaratnya seorang muslim memakan babi, hukumnya haram bukan. Hal tersebut sudah melekat pada diri dan pikiran setiap insan. Namun mengapa tidak dengan riba? Padahal riba 
juga di haramkan. Contoh lain yang lebih menarik dikalangan anak muda yaitu pacaran. Apakah ada yang mengatakan pacaran itu halal?

Dengan harapan bahwa kedepannya nanti adik-adik melinial ini dapat mengamalkan apa yang telah di pelajari selama 1 bulan ini. Dan dapat membuat anak-anak muda di era 4.0 ini menjadi lebih cermat dalam milih lembaga keuangan untuk simpan pinjam. Tidak hanya anakanak muda saja namun juga masyarakat sekitar nya.

Kegiatan ini dilakukan setiap minggu sekali selama empat kali pertemuan, tepat nya setiap hari sabtu. Dengan tujuan agar siswi-siswi dari SMANJ dapat menerapkan ilmu yang sudah diajarkan kepada lingkungan masyarakat disekitarnya, dan dapat membantu generasigenerasi selanjutnya dalam memahami apa itu riba. Karena dalam islam riba itu diharamkan. Namun banyak sekali masyarakat sekitar yang menutup mata akan hal tersebut. Dan dengan itu kami para mahasiswa memilih adik-adik dari SMANJ untuk mempelajari lebih dalam tentang hukum riba. Dengan harapan generasi yang lebih baik.

Pada minggu pertama kegiatan belajar mengajar dan juga diskusi bersama ini, di mulai pada pukul 11.00-12.30. Sebelum memasuki materi inti, dilakukan pretest dengan meminta siswi-siswi mengisi beberapa soal yang telah disiapkan. Setelahnya di jelaskan tentang materi dasar dari perbankan. Seperti apa itu transaksi, macam-macam transaksi, akuntansi, tentang lembaga keuangan dan juga di imbangi dengan sesi tanya jawab dan diskusi antara mahasiswa dan siswi SMANJ.

Kegiatan pada minggu kedua yaitu tanggal 20 Februari 2021, kegiatan pada hari ini hanya di isi games. Games yang dimainkan adalah spidol berjalan yang iringi music dan tunjuk bakat. Agar membuat adik-adik lebih fresh dan lebih semangat lagi dalam menambah ilmu.

Materi kegiatan yang disampaikan pada 27 Februari 2021 meliputi materi pertama tentang apa itu riba, macam-macam riba, dan hukum riba.

Dan setelah penyampaian materi pertama selesai dilakukan posttest untuk minggu ke-4 yaitu minggu terakhir. Tidak lupa juga sesi foto bersama dan pemberian cendra mata dari mahasiswa untuk XII IPS 3.

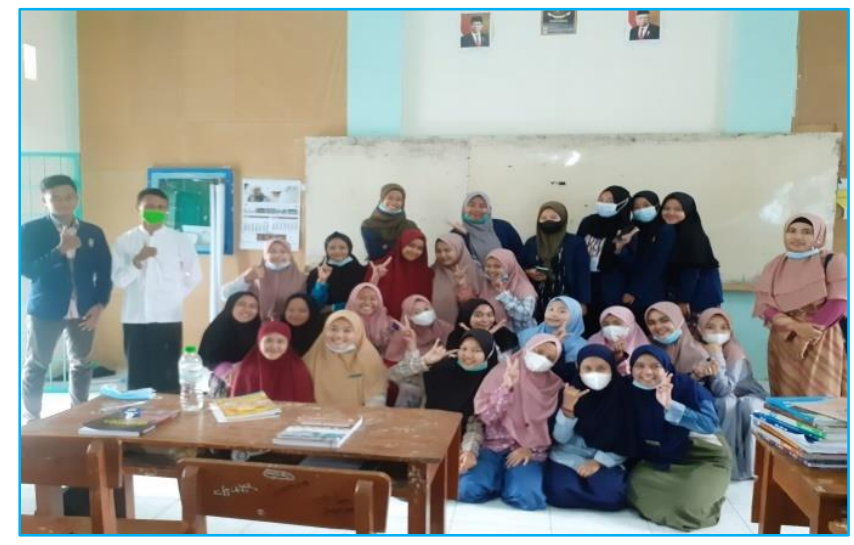

Gambar 1. Mahasiswa UNUJA bersama peserta pengabdian

Kegiatan Kuliah Kerja Nyata (KKN) ini dilaksanakan di SMA Nurul Jadid pada program keahlian IPS yang dimana tujuan kami ialah memutus rantai tentang penggunaan riba pada generasi generasi muda yang pastinya akan berguna di masa yang akan datang. Yang kedua dimana memang kompetensi keahlian pada bidang kami yang lebih mengutamakan syari'ah pada penerapan transaksi - transaksi atau produk produk pada Bank.

Kegiatan ini dilakukan mulai pukul 10.30-12.30 WIB dengan jumlah keseluruhan 22 siswi yang secara antusias mengikuti kegiatan ini dan mendukung lancarnya kegiatan kami sebagai pengabdian kepada masyarakat. Sebelum di mulainya kegiatan mengajar ini kami berinisiatif untuk melakukan pretestdengan mengerjakan soal-soal dasar mengenai transaksi sebelum kami memasuki point utama yaitu riba . Setelah mereka menyelesaikan pretest yang 
kami berikan kami melakukan pematerian dengan cara memberikan sedikit slide yang dibantu dengan microsoft power point tentang materi yang telah di pretest-kan sebelumnya.

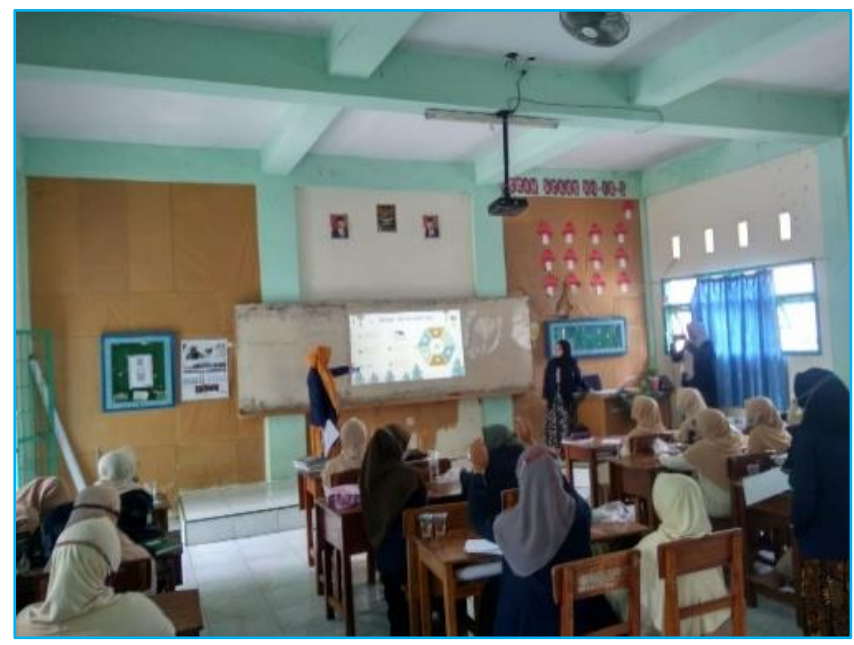

Gambar 2. Mahasiswa UNUJA sedang menjelaskan materi tentang dasar-dasar transaksi

Tabel 1. Hasil pretest siswa SMA Nurul Jadid tentang transaksi

\begin{tabular}{clcc}
\hline No & Tingkat Pengetahuan & F & \% \\
\hline 1 & $\begin{array}{l}\text { Tidak memahami tentang riba dan tidak mengetahui } \\
\text { praktek riba serta upaya dalam memberantasnya }\end{array}$ & 3 & 14 \\
2 & $\begin{array}{l}\text { Hanya mengetahui Teori tentang Riba saja } \\
3\end{array}$ & 9 & 41 \\
& $\begin{array}{l}\text { Hanya mengetahui praktek riba di masyarakat dan } \\
\text { upaya yang harus dilakukan untuk memberantasnya }\end{array}$ & 6 & 27 \\
$\quad \begin{array}{l}\text { Memahami tentang riba dan praktek yang terjadi dan } \\
\text { mengetahui upaya dalam memberantasnya }\end{array}$ & 4 & 18 \\
$\quad$ TOTAL & 22 & 100 \\
\hline
\end{tabular}

Materi mengenai transaksi pertama kali yang diberikan meliputi definisi transaksi, transaksi akuntansi dan praktek bagaimana mengelola transaksi keuangan yang benar. Seperti contoh mengenai macam akuntansi seperti audit akuntansi, akuntansi perpajakan,akuntansi keuangan dan akutansi forensik. Dari pengamatan dari pengerjaan soal transaksi ini para siswi masih banyak yang tidak paham tentang apa itu transaksi,bagaimana pengerjaan mengenai soalsoal akuntansi dan pemecahan masalahnya.

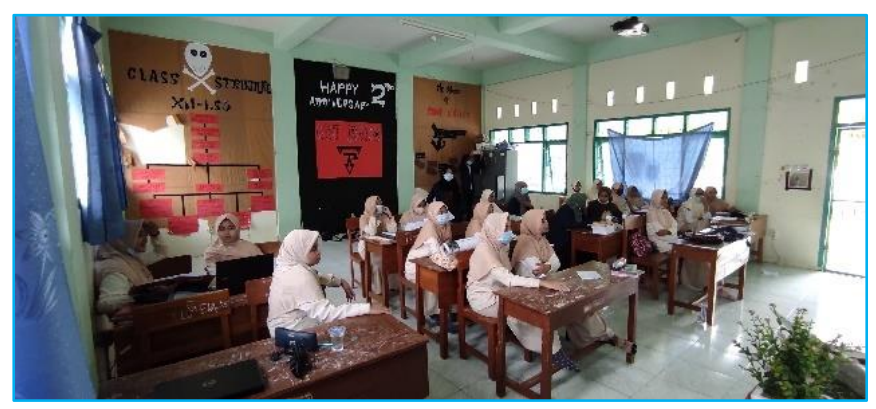

Gambar 3. Siswa SMA Nurul Jadid sedang memperhatikan materi tentang Jenis Transaksi

Setelah beberapa kali pertemuan kami laksanakan dengan berbagai macam cerita dengan berbagai macam perkenalan kepribadian baru dari siswi SMA Nurul jadid, dan juga bermacam materi dan pengetahuan baru yang kami berikan kepada mereka sampailah kami 
pada tahapan yang menjadi tujuan kami untuk memperkenalkan Bank Syari'ah serta memberitahukan tentang riba dan juga dampaknya.

Mengapa pendidikan riba itu penting untuk generasi muda? Karena merekalah yang akan meneruskan perekonomian di Indonesia, jika generasi mereka masih di pengaruhi oleh riba maka perekonomian Indonesia khususnya di Bank Syari'ah Indonesia, seperti Riba ialah setiap kelebihan antara nilai barang yang diberikan dengan nilai barang yang diterima (Abu bakar Ibnu Al Arabi, Ahkamul Qur,an)

Pada pertemuan ini kami memberikan Post -test untuk para siswi Nurul jadid dan memberikan sedikit pematerian tentang pokok utama yaitu riba yang bersangkutan dengan definisi riba, macam macam riba, dan bagaimana dalil - dalil larangan riba serta bagaimana cara kita untuk menyikapi riba.

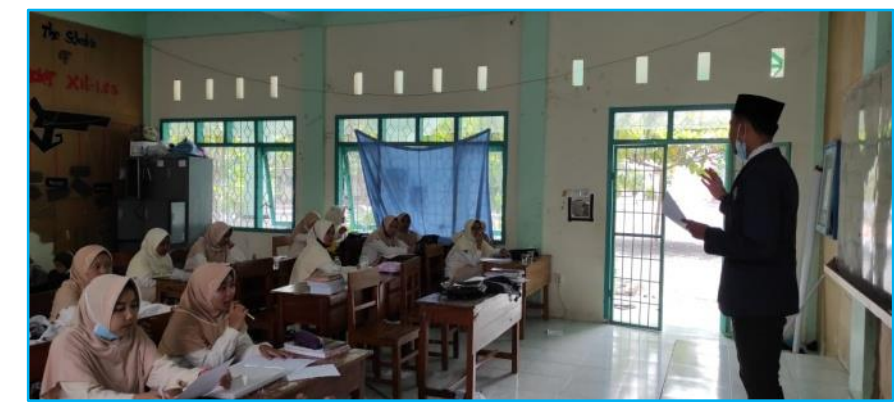

Gambar 4: Siswa SMA Nurul Jadid sedang memperhatikan materi tentang Anti Riba

Tabel 2. Hasil Post-Test

\begin{tabular}{clcc}
\hline No & Tingkat Pengetahuan & F & \% \\
\hline 1 & Tidak memahami tentang riba dan tidak mengetahui praktek riba & - & - \\
& $\begin{array}{l}\text { serta upaya dalam memberantasnya } \\
2\end{array}$ & Hanya mengetahui Teori tentang Riba saja & 18 \\
3 & $\begin{array}{l}\text { Hanya mengetahui praktek riba di masyarakat dan upaya yang } \\
\text { harus dilakukan untuk memberantasnya }\end{array}$ & 3 & 14 \\
4 & $\begin{array}{l}\text { Memahami tentang riba dan praktek yang terjadi dan mengetahui } \\
\text { upaya dalam memberantasnya }\end{array}$ & 15 & 68 \\
$\quad$ TOTAL & 22 & 100 \\
\hline
\end{tabular}

Dari data Post test diatas dapat disimpulkan bahwa setelah diadakannya pengabdian pada siswi IPS SMA Nurul jadid yang mengangkat materi tentang "Generasi Anti Riba" dan telah dijelaskan pokok pokok utama dari riba, mereka telah banyak mendapat pelajaran dan memahami cara mengantisipasi penggunanaan riba terlebih pada transaksi syari'ah, serta berjanji untuk selalu berhati-hati pada setiap transaksi yang berhubungan dengan Riba tersebut.

Memang pada dasarnya riba itu sangat berpengaruh bagi masyarakat, dimana pola pikir mereka yang lebih mendahulukan cepat dan praktis terlebih lagi soal financial keuangan, tetapi jika kita menelisik lebih dalam lagi tentang bagaimana dampak riba terhadap diri kita sendiri dan nantinya juga terdampak terhadap perekonomian di Indonesia yang akan lebih menyengsarakan masyarakat miskin dan memperkaya pihak yang telah berkecukupan.

Hal ini juga sesuai dengan hasil penelitian Iwan Romadhan (2019) menyatakan bahwa kebahagian (falah) itu akan diperoleh dengan cara meninggalkan sistem riba ini, dan pada saat yang sama Al-Qur'an menyatakan bahwa kebahagiaan tidak mungkin akan diperoleh lewat praktek ribawi. Karena riba itu berdasar pada ketidakadilan.

Riba juga dapat menimbulkan over produksi. Riba membuat daya beli sebagain besar masyarakat lemah sehingga persediaan jasa dan barang semakin tertimbun, akibatnya perusahaan macet karena produksinya tidak laku, perusahaan mengurangi tenaga kerja untuk 
menghindari kerugian yang lebih besar, dan mengakibatkan adanya sekian jumlah pengangguran [3].

\section{KESIMPULAN}

Target dan luaran yang dihasilkan pada program pengabdian masyarakat ini adalah peningkatan pengetahuan serta kesadaran pada Siswa SMA Nurul Jadid tentang pentingnya pengetahuan tentang transaksi yang benar yang sesuai syariat Islam dengan upaya mampu meningkatkan ekonomi pesantren pada khususnya dan ekonomi Indonesia pada umumnya.

Sesuai dengan target dari kegiatan pengabdian ini, maka dihasilkan bahwa siswa SMA Nurul jadid, telah memiliki kesadaran dan pemahaman yang baik tentang transaksi yang sesuai dengan hukum ekonomi Islam, selain dari itu dengan mengetahui transaksi yang sesuai, siswa SMA Nurul Jadid bisa mempraktekkan pada kehidupan sehari-hari. Tolak ukur dari keberhasilan ini adalah, hasil dari post test yang telah dilaksanakan, menunjukkan mayoritas siswa SMA Nurul Jadid telah paham tentang transaksi yang seuai dengan hukum ekonomi Islam.

Khusus pada permasalahan tentang Riba yang merupakan bagian dari transaksi keuangan syariah yang harus dihindari, siswa SMA Nurul Jadid, telah mengetahui dengan baik tentang bentuk riba tersebut. Penyampaian materi tentang konsep riba, fenomena riba yang terjadi di masyarakat dan upaya dalam memberantaskan riba, mampu memberikan gambaran kepada siswa terkait hal yang harus dilakukan setelah terjun ke masyarakat nantinya. Harapannya dengan kegiatan pengabdian ini, siswa SMA Nurul Jadid memiliki kesadaran untuk menjauh praktek-praktek riba.

\section{UCAPAN TERIMA KASIH}

Pada pelaksanaan pengabdian ini, kami dari Program Studi Perbankan Syariah Fakultas Agama Islam Universitas Nurul Jadid, mengucapkan terimakasih sebesar-besarnya kepada Kepala SMA Nurul Jadid, Ketua Program IPS, Guru Mapel Ekonomi, dan seluruh Siswa yang terlibat pada kegiatan pengabdian ini, besar harapan kami, kegiatan ini akan menjadi bekal masa depan siswa untuk selalu berhati-hati pada transaksi yang berbau Riba.

\section{DAFTAR PUSTAKA}

[1] D. I. Kelas, V. I. I. Smp, and N. Palembang, "MELALUI METODE GROUP TO GROUP EXCHANGE bisa dimaknai untuk masa kini, dan beberapa hal yang menjadi kajian IPS . abstrak , yaitu konsep peranan peristiwa proses pengorganisir dan memaknai fakta yang ada di kelas VII SMP yaitu Materi memenuhi kebutuhan me," vol. 5, no. 1, pp. 49-55, 2020.

[2] A. N. R. Muhammad Anwar Fathoni, "Peran Pesantren dalam Pemberdayaan Ekonomi Umat di Indonesia," Proceeding Conf. Islam. Manag. Accounting, Econ., vol. 2, pp. 133-140, 2019.

[3] A. Jamarudin, M. K. Anam, and O. C. Pudin, "Bahaya Riba Dalam Ekonomi Islam Dalam Perspektif Al-Qur'an," Stat. F. Theor, vol. 53, no. 9, pp. 1689-1699, 2019.

[4] L. Istiqomah, "Konsep Riba dalam Al-Qu'an dan Implikasinya Bagi Perekonomian," Perbank. Syariah, vol. 1, no. 1, pp. 41-56, 2020.

[5] A. T. Buhari, "Bank Dan Riba: Implikasinya Dalam Ekonomi Islam," J. Stud. Keislam., vol. 6, no. 1, pp. 127-136, 2020, doi: https://doi.org/10.35309/alinsyiroh.v6i1.3824.

[6] S. Sudanto, "Pelarangan riba dan bunga dalam sistem hukum kontrak syariah," Teraju, vol. 1, no. 02, pp. 89-104, 2020, doi: 10.35961/teraju.v1i02.93.

[7] A. D. Putra and R. Desiana, "Pertukaran dan Percampuran dalam Ekonomi," Muamalatuna, vol. 12, no. 1, p. 123, 2020, doi: 10.37035/mua.v12i1.3310.

[8] A. Amwal, “| Al Amwal: Vol. 1, No. 2, Februari 2019,” vol. 1, no. 2, pp. 49-69, 2019. 
[9] Maida Khairani, "Sikap Karir (Studi Kasus pada Komunitas Masyarakat Anti Riba Pekanbaru)," pp. 1-92, 2020.

[10] S. Nurlaila, "Pandangan Ibrahim Hosen dan Yusuf al-Qaradhawi mengenai status hukum bunga bank."

[11] H. Latif, “Bahaya Riba dalam Perspektif Hadits," J. Ilm. Al Mu'Ashirah, vol. 17, no. 2, p. 176, 2020.

[12] A. Naufal, "Riba Dalam Al-Quran Dan Strategi Menghadapinya," Al Maal J. Islam. Econ. Bank., vol. 1, no. 1, p. 100, 2019, doi: 10.31000/almaal.v1i1.1838.

[13] J. Aryani, S. Suparmin, and Y. Samri, "Analisis Efektivitas Kontribusi Komunitas Masyarakat Tanpa Riba," TANSIQ J. Manaj. Dan Bisnis Islam, vol. 2, no. 2, 2019.

[14] "RIBA VS ZAKAT DALAM PERPEKTIF EKONOMI ISLAM Iwan Romadhan Sitorus IAIN Bengkulu A . PENDAHULUAN Zakat merupakan salah satu pilar dari pilar Islam yang lima . Allah SWT telah mewajibkan bagi setiap muslim untuk mengeluarkannya sebagai penyuci harta mereka," vol. 5, no. 1, pp. 102-118, 2019. 